\title{
Incorporation of Laminarin-Based Hydrogel with Graphene Foam to Enhance the Toughness of Scaffold and Regulate the Stem Cell Behavior
}

Lin Feng ${ }^{\text {a, }}$, Ying Hao ${ }^{\text {b, * }}$, Mo Zhu ${ }^{\text {b }}$, Yuanxin Zhai ${ }^{\text {a, }}$, Lingyan Yang ${ }^{\text {a, }}$, Yang Liu ${ }^{\text {b }}$ and Guosheng Cheng a, b, *

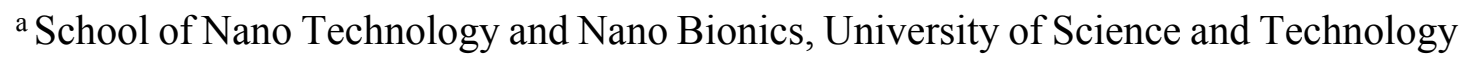
of China, Hefei 230026, P. R. China

${ }^{\mathrm{b}}$ CAS Key Laboratory of Nano-Bio Interface, Suzhou Institute of Nano-Tech and Nano-Bionics, Chinese Academy of Sciences, Suzhou 215123, P. R. China

* Corresponding authors

Email: Tel: 86-051262872629. E-mail: yhao2017@sinano.ac.cn (Ying Hao);

Tel: 86-051262872557. E-mail: gscheng2006@sinano.ac.cn (Guosheng Cheng) 


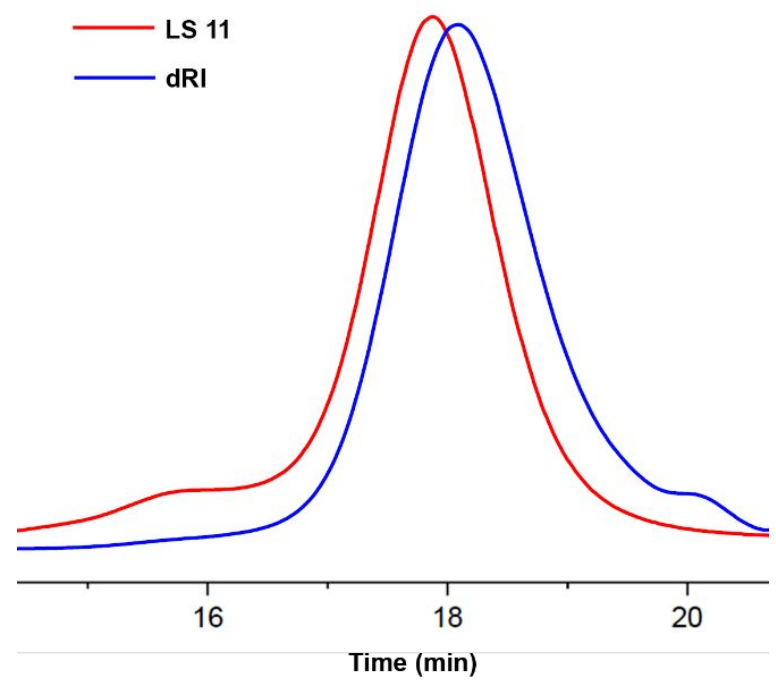

Figure S1. Chromatograms from SEC-MALLS for laminarin from differential refractive index (dRI) detector and $90^{\circ}$ light scattering detector (LS 11) reveal the calculated $M_{\mathrm{w}}$ and PDI as $31.8 \mathrm{~kg} / \mathrm{mol}$ and 1.37 , respectively.

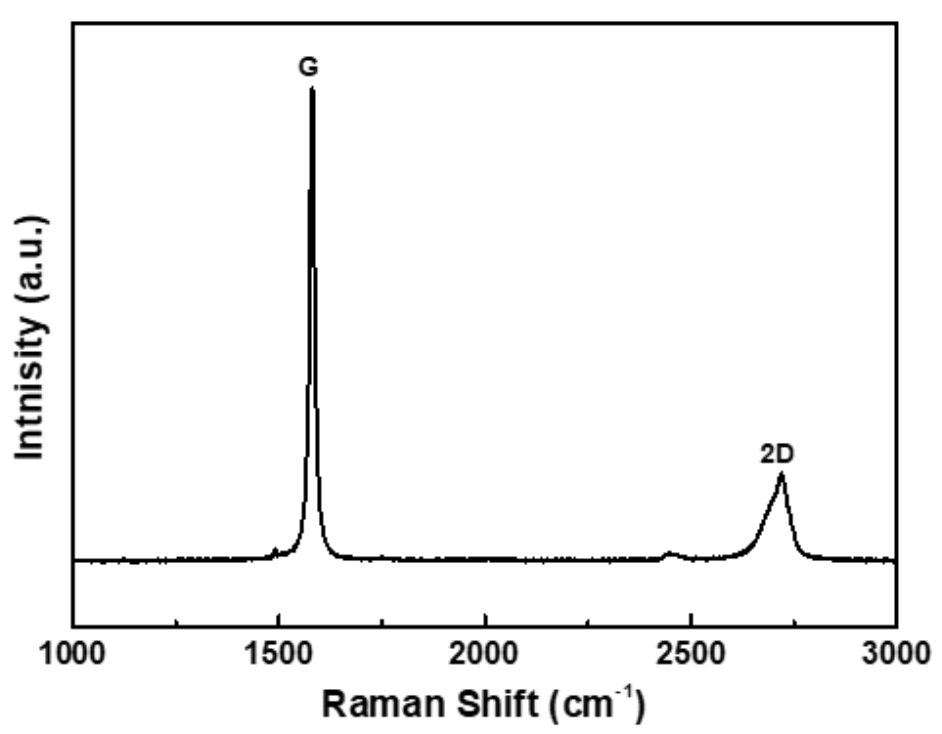

Figure S2. Typical Raman spectrum of 3D GF. 


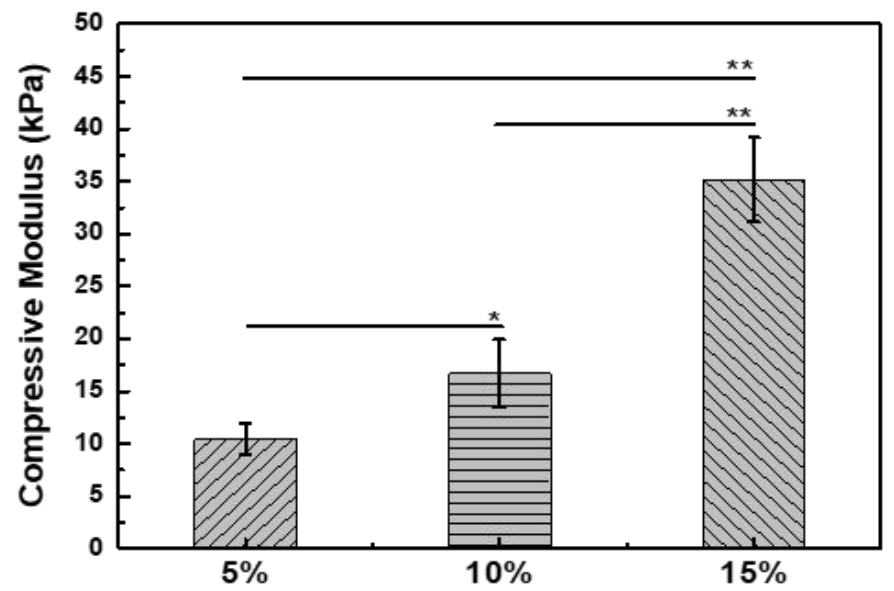

Figure S3. The compressive modulus of the composite scaffold formed by LAgel at different concentrations of LA-MA. 